\title{
RELATIONSHIPS BETWEEN SINKHOLE-RELATED FEATURES AND INSAR-DETECTED SUBSIDENCE POINTS IN WEST CENTRAL FLORIDA
}

Tonian Robinson

University of South Florida, 4202 E Fowler Ave., Tampa, Florida, 33620,U.S., tonianr@mail.usf.edu

Christine Downs

University of South Florida, 4202 E Fowler Ave., Tampa, Florida, 33620, U.S., cmdowns@usf.edu

Talib Oliver-Cabrera

Florida International University, 11200 SW 8th St., Miami, FL, 33199,U.S., toliverc@fiu.edu

Boya Zhang

Florida International University, 11200 SW 8th St., Miami, FL, 33199, U.S., bzhan018@fiu.edu

Sarah Kruse

University of South Florida, 4202 E Fowler Ave., Tampa, Florida, 33620,U.S., skruse@usf.edu

\section{Shimon Wdowinski}

Florida International University, 11200 SW 8th St., Miami, FL, 33199, U.S., swdowins@fiu.edu

\begin{abstract}
Sinkholes in west-central Florida are usually formed from the erosion of overlying soil and sediment into open fissures of dissolved limestone bedrock. They are one of the leading natural disasters in the area, and therefore, precursory detection is crucial to alleviate risks of property damage. Using the Interferometric Synthetic Aperture Radar (InSAR) method, we can detect surface subsidence in selected study areas over which InSAR scenes were captured every $22-45$ days over $\sim$ two years. InSAR is an airborne remote sensing technique that uses multiple Synthetic Aperture Radar (SAR) images to resolve elevation changes over time. Using the Persistent Scatterer Interferometry (PSI) method, processed InSAR datasets can be used to create time-series datasets of localized subsidence. We complete a statistical analysis to determine if individual InSAR time series points show evidence of discontinuous behavior (as might be expected for sinkhole activity), which could be indicated by a slope break within the time-series. These time-series points with statistically identified slope breaks are compared against other terrain data. We examine the relationship between subsidence rates and distance from surface water features identified from both aerial images from 1944 and present surface water features from the USDA database. The proximity of InSAR points to surface water features was determined using the NEAR
\end{abstract}

analysis technique in ArcGIS Pro. This analysis shows a weak correlation between subsidence rates and distance to both past and present surface water features. We also examined how subsidence rates relate to the elevation of the study area. This analysis shows no correlation between subsidence rate and local elevation.

\section{Introduction}

West-central Florida is considered "sinkhole alley" due to its high rate of sinkhole activity. Sinkholes in this region are usually formed from the erosion of overlying soil and sediment into open fissures of dissolved limestone bedrock (Tihansky, 1999). Since sinkholes are one of the leading natural disasters in this area, precursory detection is crucial to alleviate the risks of property damage. Detection of surface subsidence is possible using the Interferometric Synthetic Aperture Radar (InSAR) method. Synthetic Aperture Radar (SAR) is a radar technique used to create high-resolution images of the Earth's surface, InSAR uses the difference in phase between two SAR images to create elevation models (Burgmann et al., 2000). The InSAR technique has a millimeter-scale vertical resolution and therefore can detect small surface changes. It also allows for spatial analysis of potentially sinkhole - related features on a regional scale. The method has been successfully used to assess sinkhole deformation in the Dead Sea region (Nof et al., 2019; Atzori et al., 2015; Yechieli et 
al., 2016). Imaging sinkholes in Florida is much more difficult due to vegetation that lowers the coherence of SAR images and the smaller diameter (up to $5 \mathrm{~m}$ ) of Florida sinkholes (Oliver-Cabrera et al., 2018). Therefore, to help assess the use of InSAR time series datasets for detection of sinkhole-related subsidence in west-central Florida, we seek to understand the relationship between subsiding points and karst-related surface and hydrological features.

Previous research approaches focused on creating hazard and risk maps and models for sinkholes using already collapsed sinkhole locations (Frumkin et al., 2011; Tharp, 1999). Other studies delineated sinkhole occurrences as they related spatially to drywell complaints, differences in groundwater head, and other surface hydrological features (Aurit et al., 2013; Whitman, 1999). This work analyzes the spatial distribution of possible sinkhole locations identified from InSAR-derived time-series datasets showing subsidence in west-central Florida. We use aerial photos to see how surface water features in the 1940s relate to current InSAR-detected subsiding areas. A digital elevation map (DEM) of the study area, retrieved from the USGS National Elevation Dataset, is also used to compare local subsidence and elevation.

\section{InSAR Data Acquisition and Analysis}

InSAR data acquisition was completed by the TerraSAR-X satellite with an X-band sensor. The repeatpass interferometry and spotlight acquisition mode were used to collect high-resolution data $(0.25$ to $1.1 \mathrm{~m}$ pixel resolution) between the years 2015-2018 for three site locations in West Florida (Figure 1). Due to budget constraints InSAR acquisition is limited to a two-year sampling period. For this paper, we focus on one of the three sites, site 2, which is $15 \mathrm{~km}^{2}$ in area. The Stanford Method (StaMPS) software was used to implement the Persistent Scatter Interferometry (PSI) method to produce displacement information for three site locations in west-central Florida (Oliver-Cabrera et al., 2018).

\section{Methodology}

To analyze the relationship of InSAR derived subsidence points and surrounding surface water and topography, we first complete a statistical analysis to identify points within each time series that indicated a sudden surface movement. These sudden changes in movement (slope breaks) are assumed related to sinkhole formations and therefore used as a selection criterion for the InSAR points used in this paper. We then use spatial techniques

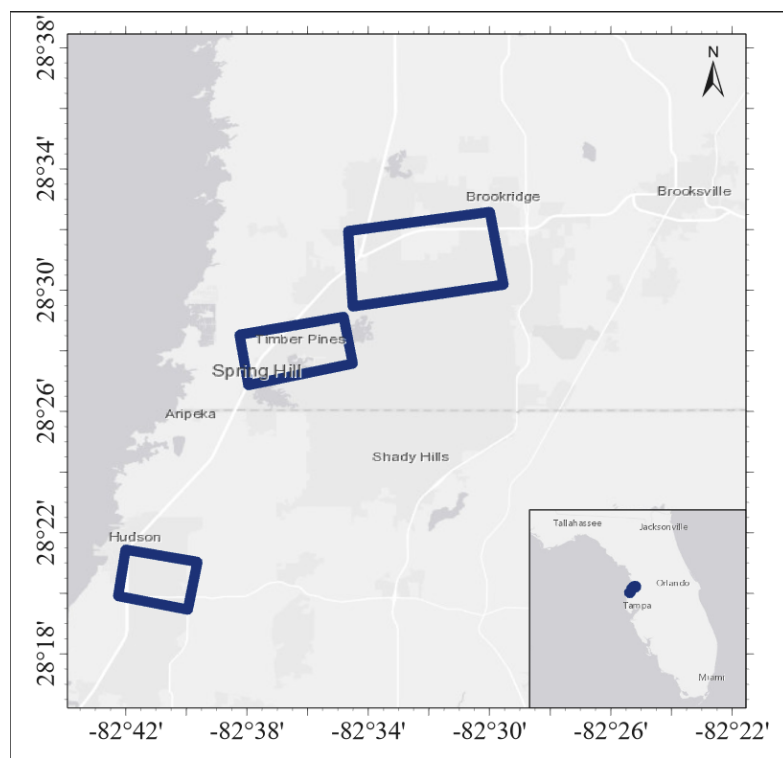

Figure 1. InSAR study area in west-central Florida. This study focuses on site 2 (middle), which is $15 \mathrm{~km}^{2}$.

in GIS: extract DEM elevation at each InSAR subsidence point and NEAR analysis to understand how time series datasets with defined slope breaks relate spatially to other surface features.

\section{Slope Break Analysis}

Slope break analysis was carried out using Matlab, where a single model with the slope and intercept of two lines was fitted to each time series. A kink in this two-line model was shifted throughout the selected time series to calculate line statistics for locating points of sudden surface movement (Figure 2). The time of a possible slope break was determined by finding the model fit where both lines before and after the selected kink had the lowest combination of slope uncertainty values. A p-test was then computed to determine if the points were statistically better represented by a two-line fit than a single line regression. For this study, we used the time series datasets best represented by a two-line fitted (kink) model with the assumption that they may represent sinkhole-related activity. The subsidence rate for each point used in the analysis described here, however, is the best-fit value to the total time series (e.g., blue line in Figure 2).

\section{GIS methods Digitizing Aerial Photos, Near Analysis}

Aerial photos from 1944 from the University of Florida (UF) library database were georeferenced in ArcGIS 


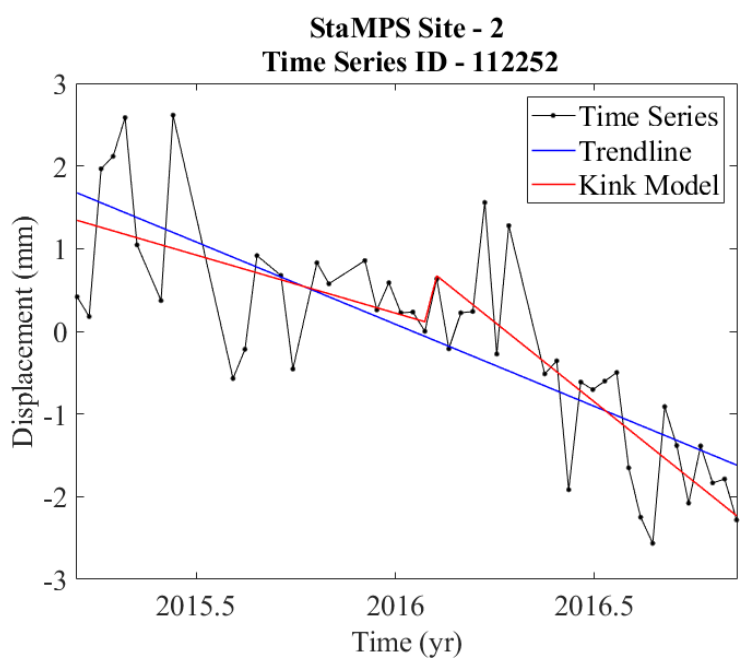

Figure 2. Example of a time-series dataset with slope break/offset location. To find the location of a slope break a two-line model is moved along the time series. The kink model is then selected by comparing slopes of the lines before and after the kink, the model with the lowest combination of slope uncertainties is selected. The slope break for this dataset is in early 2016.

Pro. Areas that were apparent surface water features were digitized for analysis. These water features had low pixel values similar to pixel values of the present-day water features (Figure 3). Surface water features can be seen in Figure 4. Using the Near Analysis geoprocessing tool, the distances between each time-series point and their nearest surface water polygon features were calculated. This was applied to polygon features from both the USDA surface water hydrography layer and the digitized surface water features from the 1944 aerial imagery. Results for the distance analysis are present in Figure 6. Figure 5 shows a plot of the relationship between the time-series slopes and elevation.

\section{Results and Discussion}

In Figure 4 the USDA surface water features outnumber the surface water features identified in the 1944 aerial imagery, therefore as we would expect the time-series points are closest to surface water features in this layer (Figure 6).

NEAR analysis values show that faster subsiding points are on average closer to water features in both the 1944 and the USDA surface water features (Figure 6). Surface water fea-

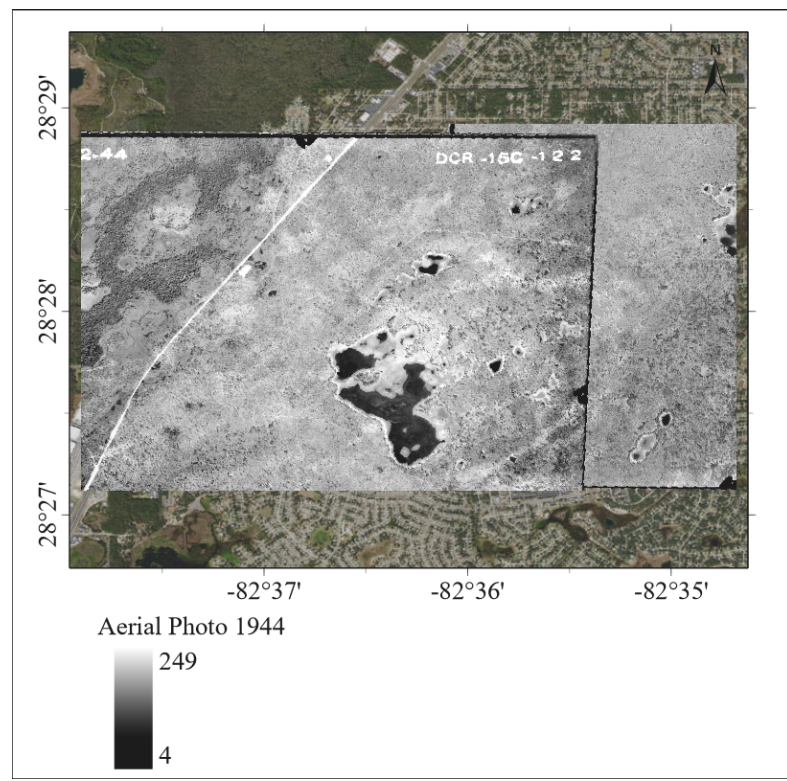

Figure 3. Image of site location in west central Florida overlain by a georeferenced aerial image from 1944. Surface water features can be identified by low (black) pixel values. Site is located in Hernando County, Florida.

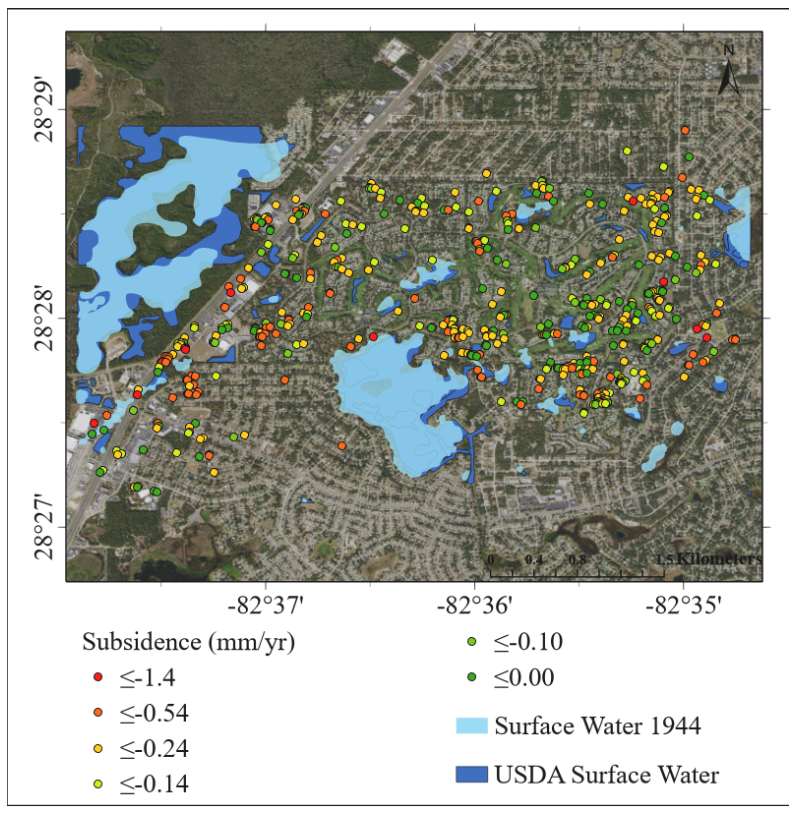

Figure 4. Map of digitized surface water features from the 1944 aerial imagery in Figure 3 and surface water features from the USDA. Time-series subsidence points are also on map. 
tures from 1944 can be assumed a representative of older collapses and therefore one might expect faster subsidence points to be in closer proximity to these older features (Figure 6 - bottom). This relationship, however, is not strong.

Figure 5 shows little to no correlation between subsidence rates and elevation. This suggests that InSAR-detected subsidence points are dispersed across the landscape without regard to elevation. However, we note that sinkholes in Florida are typically $3-5 \mathrm{~m}$ in width, which is close to the resolution of the $3 \mathrm{~m}$ DEM. Thus, the DEM will not show any small depressions that could indicate sinkhole formations. The geological significance of the elevation data can also be affected by human development of land within the area. Also, the top of limestone is very irregular and partially controls topography (Downs, 2017). Regional wetlands hydrology shows a connection between surface water and the confined Upper Floridan Aquifer. These wetlands are found in both uplands and lowlands suggesting karst features, which also drive sinkhole activity, are at least partially controlled by other factors besides topography.

\section{Conclusion}

The distance of points to surface water features from both the digitized 1944 aerial imagery and USDA hydrography shows a weak correlation to subsidence rates. InSAR subsidence rates in the study area do not correlate with elevation. To further this analysis, using

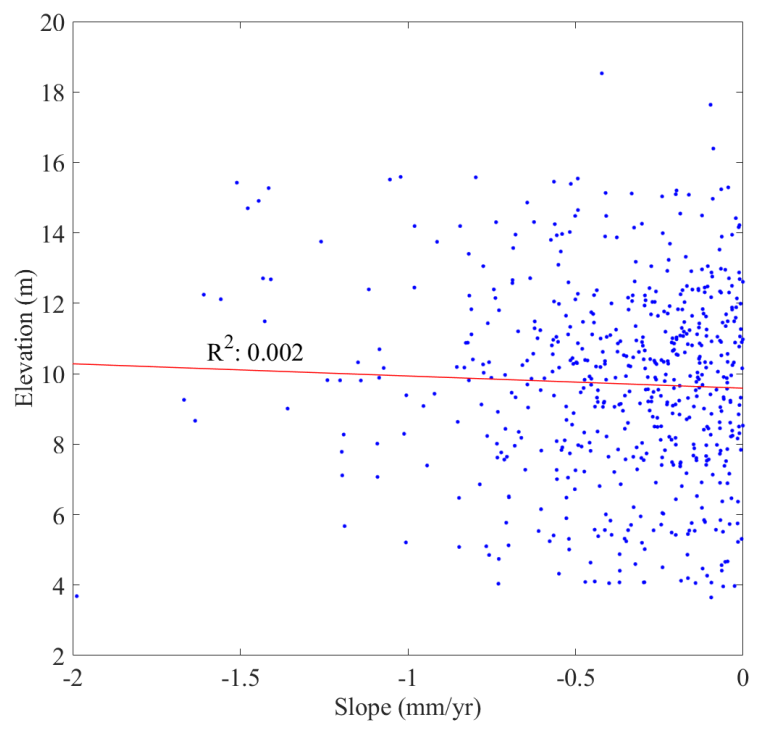

Figure 5. Relationship between elevation from 3-meter DEM (USGS-National Elevation Dataset) of study area and slope of subsidence points.
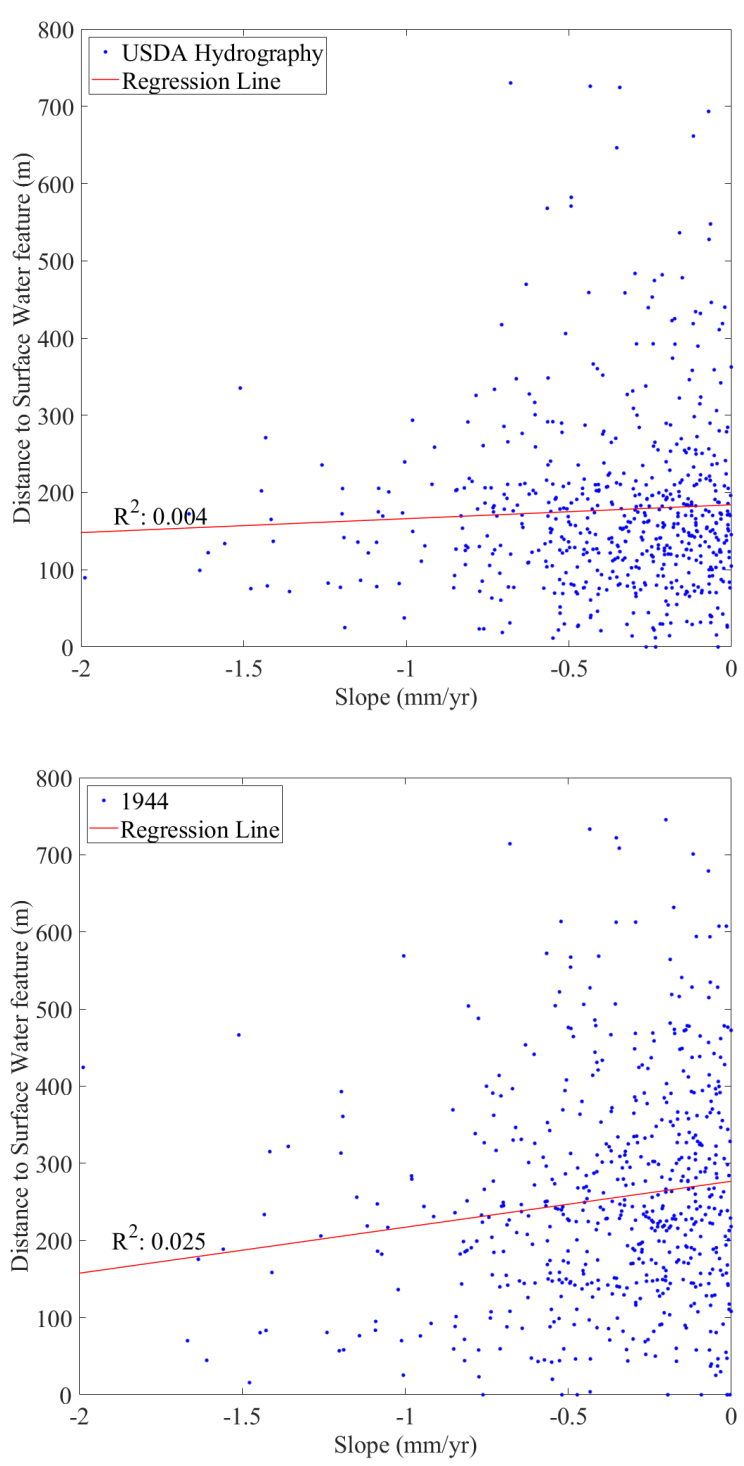

Figure 6. Plots showing the correlation between subsidence rate of each time series point and their distances to the closest water feature from the USDA layer (top) and the 1944 digitized water features (bottom).

higher resolution elevation models, we will complete a Depression/Sink Evaluation to determine the location of possible sinks in the survey area. We will also complete a principal component analysis (PCA) to identify how topographic, anthropogenic (land use land cover), and hydrological activities relate to the distribution and slope of the InSAR derived subsidence points.

\section{References}

Aerial photographs of Hernando County - Flight 15C (1944). Map and Imagery Library, George A. 
Smathers Libraries, University of Florida. U.S. Department of Agriculture. https://ufdc.ufl.edu/ UF00071753/00.

Atzori S, Baer G, Antonioli A, Salvi S. 2015. InSARbased modeling and analysis of sinkholes along the Dead Sea coastline Geophysical Research Letters 42 (20), 8383-8390. https://doi. org/10.1002/2015gl066053.

Aurit M, Peterson R, Blanford J. (2013). A GIS Analysis of the Relationship between Sinkholes, Dry-Well Complaints and Groundwater Pumping for Frost-Freeze Protection of Winter Strawberry Production in Florida PLoS ONE 8 (1), e53832. https://doi.org/10.1371/journal.pone.0053832.

Bürgmann R, Rosen P, Fielding E. 2000. Synthetic Aperture Radar Interferometry to Measure Earth's Surface Topography and Its Deformation Annual Review of Earth and Planetary Sciences 28(1), 169-209. https://doi.org/10.1146/annurev. earth.28.1.169.

Downs C. 2017. Imaging Wetland Hydrogeology: Applications of Critical Zone Hydrogeophysics to Better Understand Hydrogeologic Conditions in Coastal and Inland Wetlands and Waters [dissertation]. Tampa (FL): University of South Florida. $111 \mathrm{p}$.

Frumkin A, Ezersky M, Al-Zoubi A, Akkawi E, Abueladas A. 2011. The Dead Sea sinkhole hazard: Geophysical assessment of salt dissolution and collapse Geomorphology 134(1-2), 102-117. https://doi.org/10.1016/j.geomorph.2011.04.023.

National Elevation Dataset. 201. https://nationalmap. gov/3DEP/. U.S Geological Survey.

National Geospatial Program, 2019, USGS National Hydrography Dataset Best Resolution (NHD) for Hydrologic Unit (HU) 4 - 0310: U.S. Geological Survey.

Nof R, Baer G, Ziv A, Raz E, Atzori S, Salvi S. 2013. Sinkhole precursors along the Dead Sea, Israel, revealed by SAR interferometry Geology 41 (9), 1019-1022. https://doi.org/10.1130/g34505.1.

Oliver Cabrera T. "InSAR Applications for Environmental and Hazard Monitoring." 2018. Open Access Dissertations. 2126. https://scholarlyrepository.miami.edu/oa dissertations/2126.

Tharp T. 1999. Mechanics of upward propagation of cover-collapse sinkholes Engineering Geology 52(1-2), 23-33. https://doi.org/10.1016/s00137952(98)00051-9.

Tihansky AB. 1999. Sinkholes, west-central Florida A link between surface water and ground water, in: Galloway D, Jones DR, Ingebrtsen SE, 1999, Land Subsidence in the United States: U.S. Geological Survey, Circular 1182, p. 121-141.

Whitman D, Gubbels T, Powell L. 1999. Spatial Interrelationships between Lake Elevations, Water Tables, and Sinkhole Occurrence in Central Florida: A GIs Approach. Photogrammetric Engineering and Remote Sensing. 65. 1169-1178.

Yechieli Y, Abelson M, Baer G. 2016. Sinkhole formation and subsidence along the Dead Sea coast, Israel Hydrogeology Journal 24 (3), 601612. https://doi.org/10.1007/s10040-015-1338-y. 